SHORT REPORT

\title{
Solitary epithelial cells in B cell gastric MALT lymphoma
}

\author{
J Sutak, C Stoddard, M E F Smith
}

J Clin Pathol 2005;58:1226-1228. doi: 10.1136/icp.2004.023747

Background: Gastric mucosa associated lymphoid tissue (MALT) lymphoma is a low grade B cell lymphoma histologically characterised by neoplastic $B$ cells surrounding follicles in a marginal zone pattern and selectively infiltrating epithelium to form characteristic lymphoepithelial lesions.

Aims: To identify solitary epithelial cells in gastric MALT lymphoma and investigate their nature.

Methods: Anonymised endoscopic biopsies from eight B cell gastric MALT lymphomas and 10 control biopsies from chronic atrophic gastritis were selected. The numbers of solitary cytokeratin positive epithelial cells were assessed both semiquantitatively and quantitatively in immunostained sections. Chromogranin A expression was studied in sections consecutive to those stained for cytokeratin.

Results: Statistical analysis of the quantitative data confirmed that solitary epithelial cells were significantly more common in the lymphomas. The study of consecutive sections showed that the single cells express chromogranin A.

Conclusions: The presence of solitary, cytokeratin positive epithelial cells within the neoplastic infiltrate is a characteristic feature of gastric B cell lymphoma. These solitary epithelial cells are of neuroendocrine origin.

G astric mucosa associated lymphoid tissue (MALT) lymphoma, "extranodal marginal zone B cell lymphoma of mucosa associated lymphoid tissue" (World Health Organisation classification), is a low grade B cell lymphoma. It has an indolent course, tending to remain localised to the stomach for long periods, and seldom disseminating to the bone marrow. Histologically, these lymphomas recapitulate the structure of MALT and, like other lymphomas, contain several different components, not all of which are neoplastic. The neoplastic component of MALT lymphomas consists of the B cells surrounding reactive follicles and selectively infiltrating the epithelium to form the characteristic lymphoepithelial lesions. ${ }^{1}$ Although the lymphoepithelial lesion has been well characterised, there has been no detailed description of solitary epithelial cells to our knowledge. We performed an immunohistochemical investigation of gastric MALT lymphoma, using cases of chronic atrophic gastritis as controls, to determine the frequency and nature of solitary epithelial cells in these conditions.

"The neoplastic component of mucosa associated lymphoid tissue lymphomas consists of the B cells surrounding reactive follicles and selectively infiltrating the epithelium to form the characteristic lymphoepithelial lesions"

\section{METHODS}

Anonymised endoscopic gastric biopsies were obtained from eight B cell marginal zone MALT lymphomas and 10 control cases of chronic atrophic gastritis. Sections were
Table 1 Semiquantitative assessment of the histological parameters in MALT lymphoma and atrophic gastritis

\begin{tabular}{|c|c|c|c|c|}
\hline Sample & $\begin{array}{l}\text { Density of } \\
\text { lymphocytic } \\
\text { infiltrate (1-3) }\end{array}$ & $\begin{array}{l}\text { Presence } \\
\text { of } \\
\mathrm{H} \text { pylori }\end{array}$ & $\begin{array}{l}\text { No. of single } \\
\text { cytokeratin } \\
\text { positive cells }\end{array}$ & $\begin{array}{l}\text { No. of LE } \\
\text { lesions }\end{array}$ \\
\hline \multicolumn{5}{|c|}{ MALT lymphoma } \\
\hline L1 & 3 & - & 6 & 5 \\
\hline L2 & 3 & - & 35 & 11 \\
\hline L3 & 3 & + & 1 & 2 \\
\hline L4 & 3 & ++ & 10 & 11 \\
\hline L5 & 3 & + & 7 & 7 \\
\hline L6 & 3 & - & 2 & 6 \\
\hline L7 & 3 & - & 5 & 4 \\
\hline L8 & 3 & + & 2 & 3 \\
\hline \multicolumn{5}{|c|}{ Atrophic gastritis } \\
\hline G1 & 3 & + & 0 & 0 \\
\hline G2 & 1 & - & 0 & 0 \\
\hline G3 & 1 & - & 1 & 0 \\
\hline G4 & 2 & - & 0 & 0 \\
\hline G5 & 3 & ++ & 0 & 0 \\
\hline G6 & 1 & - & 0 & 0 \\
\hline G7 & 2 & - & 1 & 0 \\
\hline G8 & 3 & + & 0 & 0 \\
\hline G9 & 2 & ++ & 0 & 0 \\
\hline G10 & 1 & - & 0 & 0 \\
\hline
\end{tabular}

immunostained with a broad spectrum anticytokeratin antibody (MNF116; Dako, Ely, Cambridgeshire, UK; 1/100 dilution) after a 10 minute digestion with $0.1 \%$ trypsin $(\mathrm{pH} 7.8)$ at $37^{\circ} \mathrm{C}$, and an anti-chromogranin A antibody (Dako; 1/1500 dilution) after a 10 minute microwave pretreatment in Dako Target Retrieval Solution ( $\mathrm{pH}$ 6). The immunohistochemical technique used was a standard avidin-biotin horseradish peroxidase method (Vectastain Universal Elite ABC kit; Vector Laboratories, Peterborough, UK). We assessed the amount of lymphocytic infiltrate in the lymphoma and in the control gastritis biopsies semiquantitatively, grading it from 1 to 3 according to the Sydney classification. We recorded the Helicobacter pylori status of all lymphomas and control gastritis biopsies and the presence of lymphoepithelial (LE) lesions in the lymphoma cases. The presence of solitary cytokeratin positive epithelial cells was assessed both semiquantitatively and quantitatively. We counted the numbers of solitary cytokeratin positive epithelial cells in the lymphoid infiltrate in each MALT lymphoma biopsy and each atrophic gastritis biopsy (all biopsies were of similar size). In addition, the total numbers of solitary epithelial cells (and, separately, small isolated groups of two or three epithelial cells) were counted within standard graticule box areas, with almost all the tissue area being assessed in each case. Subsequently, the expression of chromogranin in solitary and isolated clusters of epithelial cells was studied in sections consecutive to those stained for cytokeratin.

Abbreviations: LE, lymphoepithelial; MALT, mucosa associated lymphoid tissue 

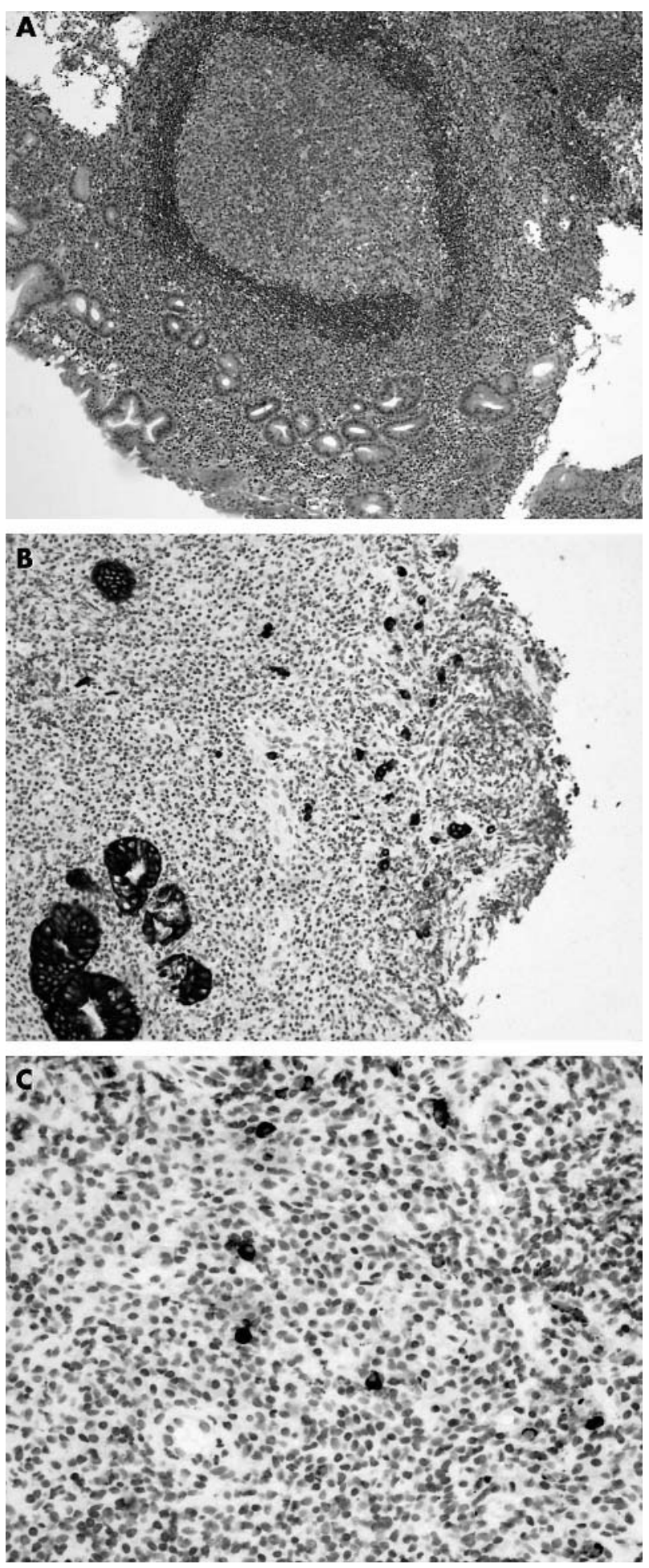

Figure 1 (A) Mucosa associated lymphoid tissue lymphoma; haematoxylin and eosin stain; original magnification, $\times 100$. (B) Solitary and small groups (two to three cells) of cytokeratin positive epithelial cells within the neoplastic lymphoid infiltrate; cytokeratin immunostain; original magnification, $\times 100$. (C) Solitary epithelial cells show positivity for chromogranin; chromogranin immunostain; original magnification, $\times 400$.

\section{RESULTS}

Table 1 shows the density of the lymphocytic infiltrate, the presence of $H$ pylori, the number of solitary cytokeratin positive cells, and the number of LE lesions within both the lymphomas and the gastritis cases.

All eight lymphomas showed a heavy lymphocytic infiltrate (fig lA) and the presence of LE lesions. Four of eight cases were positive for $H$ pylori. Solitary cytokeratin positive epithelial cells were identified within the neoplastic lymphoid infiltrate of all eight MALT lymphomas (fig 1B). The total number of endoscopic biopsies in these eight cases was 21 . The total number of such solitary epithelial cells varied between 1 and 35/case. The calculated mean value was 3.2 cells/individual biopsy.

Atrophy was present in all 10 gastritis cases, varying from mild to severe. Six of the cases showed intestinal metaplasia and four were positive for $H$ pylori. The amount of inflammation varied from mild to severe (grade 1 in four, grade 2 in three, and grade 3 in three) (fig 2). Solitary cytokeratin positive epithelial cells were identified in only two of the 10 cases, one of which was mildly inflamed and mildly atrophic, and the other of which was moderately inflamed and severely atrophic. The total number of endoscopic biopsies in these 10 cases was 24 . In both the cases in which solitary epithelial cells were seen, only a single such cell was identified. The calculated mean value for all chronic atrophic gastritis cases was 0.08 cells/biopsy.

Quantitative analysis confirmed the findings of the semiquantitative study. The mean number of solitary epithelial cells in lymphoma was $4.42 / \mathrm{mm}^{2}$ (range, 0.318.78 ), and in chronic atrophic gastritis $0.06 / \mathrm{mm}^{2}$ (range, $0.00-0.36$ ). For groups of two or three epithelial cells, the mean figures were $2.14 / \mathrm{mm}^{2}$ and $0.74 / \mathrm{mm}^{2}$, respectively. The number of solitary cyokeratin positive cells as a proportion of the number of graticule fields studied was compared between lymphoma and atrophic gastritis (the analysis being repeated for isolated groups of two or three cells). There were significantly more single cells and cell groups in lymphoma than in atrophic gastritis (for solitary cells the Mann-Witney test gave test statistic $Z=3.58, \mathrm{p}<0.01$; for cell groups $Z=2.19, \mathrm{p}=0.03)$. Therefore, the association with lymphoma was substantially greater for single cells than for cell groups.

The study of consecutive sections showed that the solitary epithelial cells and the isolated epithelial cell groups in both MALT lymphoma and chronic atrophic gastritis were strongly positive for the neuroendocrine marker, chromogranin A (fig lC).

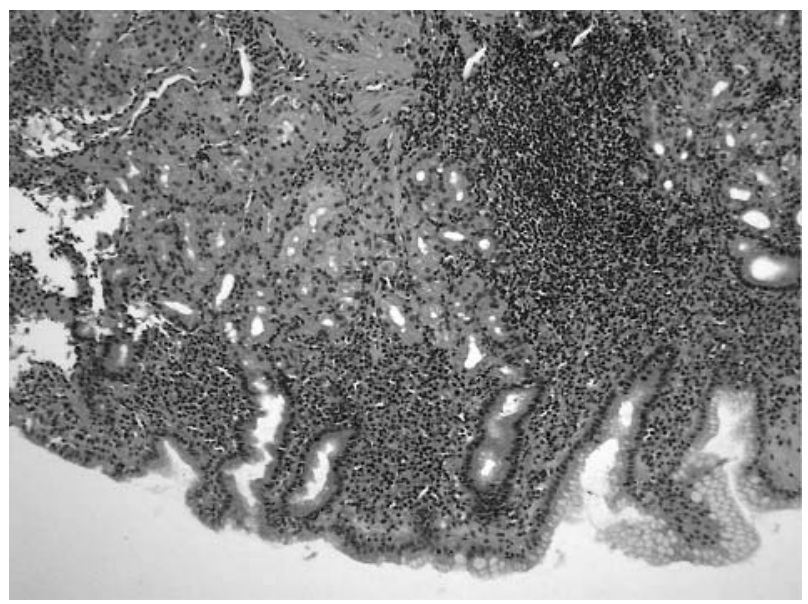

Figure 2 Control gastritis, grade 3; haematoxylin and eosin stain; original magnification, $\times 100$. 


\section{DISCUSSION}

The number of solitary cytokeratin positive epithelial cells was significantly greater in the neoplastic lymphoid infiltrate of gastric MALT lymphoma than in chronic atrophic gastritis. Although there was a denser lymphocytic infiltrate in the lymphoma cases, some of the gastritis cases showed a grade 3 infiltrate but had no solitary epithelial cells. Therefore, the presence of solitary epithelial cells cannot be related solely to the extent of lymphocytic infiltration. The presence and number of solitary epithelial cells showed no correlation with $H$ pylori status. The frequency of LE lesions was indicative of the frequency of solitary epithelial cells in that those cases with the most LE lesions had the most solitary epithelial cells.

"It appears that the epithelial destructive capacity of mucosa associated lymphoid tissue lymphoma leads to the formation of both lymphoepithelial lesions and to solitary epithelial cells"

The presence of these solitary epithelial cells should be considered a characteristic, but not pathognomonic, feature of gastric MALT lymphoma. It appears that the epithelial destructive capacity of MALT lymphoma leads to the formation of both LE lesions and to solitary epithelial cells. Because of the greater architectural and cytological complexity of LE lesions, it may be that solitary epithelial cells form from LE lesions and represent an epithelial end stage relatively resistant to lymphoma destruction. Our study showed that the solitary epithelial cells are of neuroendocrine origin by the demonstration of chromogranin positivity. ${ }^{2}$ This is of interest because neuroendocrine cells have been shown to be relatively resistant to lymphoid destruction in other contexts-for example, in intestinal graft versus host disease. ${ }^{3}$ This relative resistance to destruction may in part be mediated by the fully differentiated nature of this cell type, which lacks proliferative capacity. ${ }^{4}$

The identification of solitary epithelial cells may possibly be useful in lymphoma diagnosis. If gastric MALT lymphoma is suspected in an initial haematoxylin and eosin stain, a reasonable first step in investigation would be B cell (CD20), $\mathrm{T}$ cell (CD3), and cytokeratin immunostains. A lack of lymphoepithelial structures might be viewed as reassurance that a B cell infiltrate was benign. Although all lymphomas in

\section{Take home messages}

- Solitary, cytokeratin positive epithelial cells within the neoplastic infiltrate were characteristic of gastric $B$ cell lymphoma

- These single cells express chromogranin A and are therefore of neuroendocrine origin

- The identification of solitary epithelial cells may be useful in lymphoma diagnosis

our study had LE lesions, our results nonetheless suggest that if solitary epithelial cells are identified in a cytokeratin immunostain within a B cell infiltrate, even if LE lesions are absent, MALT lymphoma should be suspected, perhaps leading to further investigation through clonality studies or repeat biopsy.

\section{ACKNOWLEDGEMENTS}

We thank Dr S Shaw (School of Mathematics and Statistics at the University of Plymouth) for help with the statistical analysis.

\section{Authors' affiliations \\ J Sutak, C Stoddard, M E F Smith, Department of Histopathology, Derriford Hospital, Plymouth, PL6 8DH, UK}

Correspondence to: DrM E F Smith, Department of Histopathology, Derriford Hospital, Plymouth PL6 8DH, UK; mark.smith@phnt.swest.nhs. uk

Accepted for publication 10 March 2005

\section{REFERENCES}

1 Isaacson PG, Norton AJ. Malignant lymphoma of the gastrointestinal tract. In: Extranodal lymphomas. Edinburgh: Churchill Livingstone, 1994:15-65.

2 Voutilainen $M$, Juhola $M$, Farkkila $R$, et al. Immunohistochemical study of neuroendocrine cells at the gastric cardia mucosa. J Clin Pathol 2002; 55:767-9.

3 Lampert IA, Thorpe P, Van Noorden S, et al. Selective sparing of enterochromaffin cells in graft versus host disease affecting the colonic mucosa. Histopathology 1985;9:875-86.

4 Chang WW, Leblond CP. Renewal of the epithelium in the descending colon of the mouse. II. Renewal of argentaffin cells. Am J Anat 1971;13:101-9. 